the purpose of convincing her friends of her inability to walk. The left leg could be pushed forward tolerably well; but the right was literally dragged into a line with the other foot and then with a sudden jerk. Yesterday she again attempted to walk, and has evidently more power over the right leg. The pain in the head is in great measure removed, and the pupils are much more obedient to the stimulus of light. The hypercathartic plan of treatment, assisted by the blister, has already strikingly assisted in partially restoring the function of the disabled leg, and there is no longer a disposition to draw it over the opposite foot in walking. It appears after all-difficult as it has been to detect the more immediate cause of the disease-that the disturbance in the brain itself, if not the causa morbi, has some share in sustaining the paraplegia in this instance. "Il en resulte," says a French writer, "que les memes causes qui produisent le paralysie en general son susceptibles de donner lieu à l'hemiplegia elle même." This may be perfectly true as a general practical conclusion; but that there are occasionally, and not unfrequently, deviations to be observed in the chain of causation, having no reference to the brain or spine in the production of purely local paralyiss, of the lower extremities more especially, cannot be questioned.

25th.-Every second day since the last report the bowels have been thoroughly moved, which, so far from producing enervation, has given my patient greater command over the use of her legs; she no longer totters, but has a firmer step, and exercises more control over the muscles concerned in progression. The pain in the head and neck has disappeared, and she reads without difficulty.

30th. - The blistered surface has been allowed to heal, and the discharge has been transferred to the left arm. It is a curious circumstance, that no sooner was the cerebral irrita tion removed, than it was succeeded by pain and numbness in the metacarpal joints of the right hand, so as to prevent her communicating with a friend with whom she was most anxious to correspond. That, however, has disappeared, and I am happy to record her daily improvement. Pressure on the brain, deformity of the spinal column, or loss of parts of its bony structure, and ramollissement of the spinal marrow, are the principal causes pointed out as the forerunners of paraplegia and hemiplegia. But the intelligent practitioner, by close observation, is enabled occasionally to detect other causes, which frequently admit of removal by steady persever. ance in the use of appropriate remedies. Sir Benjamin Brodie relates the case of a gentleman who was paraplegic from "the mind having been much harassed during the previous three years." He prevailed on him to give up all attention to business, gave him bark and ammonia, sent him into the country, and purged him freely with the compound decoction of aloes. He was a great deal better when Sir Benjamin saw him sometime afterwards, "although he had not completely recovered the use of his limbs."* The sequel of this case is not given us, but it is fair to infer that by persevering in the treatment, the gentleman was eventually restored to health.

October 8th.-My patient quits her bed daily, and is in exery respect improving. The blistered surface on the arm is allowed to heal, in consequence of an attack of strangury supervening. With a view of restoring tone to the constitution, and repairing the energy of the muscular apparatus more especially, the following mixture has been prescribed:Take of disulphate of quinine, twelve grains; dilute sulphuric acid, and the compound tincture of cardamoms, of each one drachm; water, three ounces. Dose, a third part night and morning. This plan of treatment was pursued during the succeeding four months, and the bowels were briskly acted on every second or third day. The tone of the muscular system gradually returned, and the impaired nervous energy of the lower extremities gave way to the permanent separation of those tissues by which functions of an abnormal description were produced and sustained. The celebrated Liebig main tains, and very speciously, too, that the nitrogenized vegetable principles, such as quinine, "take a share in the formation of new, or the transformation of existing, brain and nervous matter." + I speak of quinine more particularly at the present moment, because our attention is drawn to that alkaloid in the treatment of the case before us; but the alkaloids of opium, "the elements of codeine, morphia, \&c., may," the Professor holds, "be converted into constituents of brain and nervous matter, into organs of vital energy, from which the organic motions of the body derive their origin; that these substances form a constituent of that matter, by the removal of which the seat of intellectual life, of sensation, and of consciousness, is annihilated." $\ddagger$ In fact, the animal organism is

* THE LANCET, vol. ii. for 1832-3, p. 318

† Liebig's Animal Chemistry, p. 183. capable of producing the brain and nerves " out of compounds furnished to it by vegetables." Pathological research can alone determine the amount of credit which should be given to this conclusion, although we cannot but be astonished at the profound sagacity of the philosopher, whose train of abstruse reasoning on this as well as on other points leaves us but little room to doubt the truth of his deductions, which have resulted from the most patient and laborious investigation.

Before concluding, I may perhaps be allowed to make a few observations on the listlessness which almost invariably accompanies paralytic affections. The patient, before she fully regained the use of her legs, in consequence of the profound sleep into which the servant, who was sitting up, had fallen, was obliged to quit her bed, and after descending to the lower story, let her sister in, who had been out late at night visiting her friends. The undertaking astonished her, and she was equally astonished when she reflected on the ease with which she had accomplished it. A series of such impulses might possibly have been of material assistance in the recovery; indeed, a striking case is recorded in Dr. Paris's "Life of Sir H. Davy" where implicit reliance alone on the beneficial influence of a remedy restored the patient. "Among the numerous examples on record showing the influence of imagination in the cure of diseases, the following, communicated to Dr. Paris by the late Mr. Coleridge, is very remarkable. As soon as the powers of nitrous oxide were discovered, Dr. Beddoes at once concluded that it must necessarily be a specific for paralysis. A patient was selected for the trial, and the management of it was intrusted to Sir H. Davy. Previous to the administration of the gas, he inserted a small pocket thermometer under the tongue of the patient, as he was accustomed to do upon such occasions, to ascertain the degree of animal temperature, with a view to future comparison. The paralytic man, wholly ignorant of the nature of the process to which he was to submit, but deeply impressed, from the representation of $\mathrm{Dr}$. Beddoes, with the certainty of its success, no sooner felt the thermometer under his tongue, than he concluded the talisman was in full operation, and in a burst of enthusiasm declared that he already experienced the effect of its benign influence throughout his whole body. The opportunity was too tempting to be lost; Davy cast an intelligent glance at Coleridge, and desired his patient to renew his visit on the following day, when the same ceremony was performed and repeated every succeeding day for a fortnight, the patient gradually improving during that period, when he was discharged as cured, no other application having been used."* Here, then, are two striking exemplifications of the beneficial influence of the will and of the imagination, arising from adventitious and unexpected circumstances in the treatment of paralytic affections; but these affections, of course, must have been independent of organic lesion. My patient could not have obeyed the sudden impulse, if any portion of the medulla spinalis had been subjected to serious ossific pressure; and the same observation holds good if the organism of the medulla spinalis itself, irrespective of mechanical interference, has been suffering from structural de. rangement.

Lostwithiel, February, 1848.

\section{IDIOPATHIC TETANUS (EMPROSTHOTONOS) SUCCESSFULLY TREATED BY CHLOROFORM.}

BY W. H. CARY, EsQ., M.R.C.S., \&c., Woodford, Essex.

J when going to school, Jan. 19th, 1848, the weather being extremely cold; but having occasionally complained in the same manner during the last twelve months, it was disregarded. After school-hours she was brought home, the spasm (clonic) becoming more general. She had a warm bath, was put to bed, and slept well throughout the night; but next morning, whilst tying her clothes behind her, the cramp returned, and she was unable to bring her arms forward; the abdominal muscles and flexors of the thighs approximated the nose and knees. It was then I first saw her. Purgatives, large doses of opium and ether, together with the other usual remedies, were unavailingly employed, the warm bath alone affording relief. The digestive and alimentary functions went on well, and she slept comfortably each night.

On the 25th, the sixth day, perceiving exhaustion was ensuing, and that the loss of power in deglutition and articulation occasionally happened, and the diaphragm was rigidly 
and painfully contracting, I determined to use chloroform; and accompanied by my medical friend and neighbour, Mr. Jarvis, we employed forty minims, before which she was entreating the bystanders to fall on her, and keep her down. In two minutes she was narcotised, and remained in that state fully seventeen minutes. The spasm slightly returned. At a quarter to one the same quantity of chloroform was repeated (though not constantly, so as to exercise its powers) for half an hour, which produced a sleep that continued two hours. At eight in the evening my presence occasioned some, though slight, involuntary action, which was silenced by the same dose. She slept well, and arose in the morning, at nine o'clock, quite well, in which state she has been ever since, except having slight twitchings on two occasions, when

I have since visited her.

Woodford, Essex, Feb. 1848.

\section{ON THE USE OF INDIA-RUBBER AS ADHESIVE PLASTER.}

By DOUGLAS FOX EYRE, Esq., F.R.C.S. To the Editor of THE LANCET.

Srn,-As I have not been able to learn from publications, or from my medical friends, that liquid India-rubber (that is, India-rubber dissolved in naphtha) had been used instead of adhesive plaster, I beg to make the following observations through your widely-circulated journal, should such meet with your approbation.-I am, Sir, yours, \&c.

D. F. Eyre.

If liquid India-rubber, spread upon calico, or other material, by a stiff brush, or by a knife, be used as adhesive plaster, it will be found to answer far better, in almost every case, than any other adhesive material, as it sticks firmly, is pliant, produces no irritation to the skin, and will bear lotions, or washing over it. It is also most valuable in cases where the skin requires a soft plaster of an unirritating nature for its defence, as in old persons, or others long confined to bed. In such cases, it is better to use either soft leather or the Vulcanized India-rubber, made in thin sheets; the latter, from its elasticity, is often the best, as it stretches with the skin on every movement of the body. To many kinds of wounds, from operations or otherwise, strips of thin Vulcanized India.rubber, spread with the liquid, will be found invaluable as elastic adhesive plasters, as they become firmly attached to the skin, and give way to all its movements. But should any wounded part require a portion of the plaster to be non-elastic, as in the case of operation for hare-lip, \&c., then, in order to secure such part from being stretched, a short piece of calico, about an inch in length, should be stuck upon the middle of the elastic plaster, by which means that portion would become stationary.

If a circular piece of thin Vulcanized India-rubber, about two inches in diameter, be spread with the liquid, and applied on the abdomen of an infant having umbilical hernia, and a common bandage, such as is generally used for infants, be passed lightly round the body, the protrusion will be instantly checked; and if the same plaster be again spread with the liquid and re-applied, when it comes off from time to time, no trouble will be experienced by the infant. It is not necessary to use any pad or compress.

The liquid, which is like thick treacle, and the Vulcanized India-rubber, may be procured in most large torns. (They are manufactured in Manchester by Charles Mackintosh and Co.) In most cases, the thin sheet of the Vulcanized Indiarubber, or that sold as No. 50, will be the most suitable; in other cases, the thicker, or the No. 36 , will be advisable.

The most convenient method of carrying the liquid is in one of the small, compressible bottles, used by painters, holding about an ounce, so that, on removing the screw-cap, any required quantity can be squeezed out.

The above statement will give a general idea of the subject;

the materials may of course be used in a vast variety of forms. Derby, Feb. 1848.

ON THE EMPLOYMENT OF CHLOROFORM IN STRANGULATED HERNIA; AND ON AN INSTANCE OF SPONTANEOUS EVOLUTION.

By R. A. LAFARGUE, Esq., M.R.C.S. \& L.S.A., Foleshill.

ON a recent occasion, finding I could not reduce a femoral hernia of upwards of fifty hours' strangulation, after persevering efforts with the taxis, aided by enemata, application of ice to the tumour, and the usual remedies to relieve spasmodic contraction of the fibres, except the warm bath, which was impossible, from the poverty of the individual, I sent for my friend, Mr. Parsons, of Shilton, who likewise being unsuccessful in his refforts to reduce it, we determined, as a last resource, previous to operating, to test the efficacy of the chloroform as an antispasmodic, if I may so call it, and the following were the results:-

Mr. Parsons poured from twenty to thirty drops on a handkerchief, which he immediately applied to the mouth and nostrils, while I endeavoured to return the strangulated part. The first inhalation-a deep one-was followed by a fit of coughing, as likewise the second-not so deep. At the third, a strong inhalation, which she appeared to aid by pressing with her hands the kerchief to her face, she became instantaneously insensible, and in a few moments, without any difficulty, I reduced the hernia. In fact, after slight pressure, it appeared to dart through the canal into the abdominal cavity like a shot. During the state of insensibility, the patient's eyes were fixed and staring; face rigid and rather flushed; the hands, which before pressed the handkerchief, fell upon the chest motionless, and there was no rigidity of the extremities. Immediately on recoveriug, (the state of insensibility not lasting more than a minute or two, the pulse was 90 , her face and countenance became natural, and she stated, that though she was conscious of what was going forward around her, she felt no inconvenience, but merely a sensation of something passing into her abdomen, suddenly and violently, without pain.

And now that the cacoethes scribendi is upon me, I may add, that about eighteen months back, a case nearly similar to the one placed in your columns a week or two since, and headed "Spontaneous Evolution," by Mr. V. Edwards, occurred in my practice with this difference, that I could not reach the feet in endeavouring to turn, owing to the strong contractions of the uterus. Whilst I was waiting for further medical assistance, a strong pain following twenty minutes" perfect ease, brought down the breech. The infant was soon afterwards born, and seemed to have been dead some days. Perhaps these cases, when the child is dead, are not so rare as we are taught to suppose.

Foleshill, Warwickshire, Feb. 1848.

\section{IEosptal aReports.}

WEST CUMBERLAND INFIRMARY, WHITEHAVEN. CLINICAL REPORTS FROM THE FEVER WARDS. By J. F, I'ANSON, Esq., Resident Surgeon.

A taxic Symptoms supervening on the fourth day; Death on the seventh day; Congestion of the Meningeal Vessels, and some Serons Effusion in the Ventricles, on Dissection.

CASE 3.-Michael $M-$, aged nineteen; admitted Feb. 6th, 1847.

History-An Irish labourer; has always enjoyed good health, and is of a powerful build of body; has been in England nearly three months, during which time he has had very little work, and has, consequently, been obliged to live on but very scanty food, arid that of the coarsest kind. Three days ago he began to be ill, with shivering, pain in the back and limbs, headach, sickness, want of sleep, to which was added, last night, some delirium.

Condition.- - He complains now of great thirst; a burning heat in the skin; severe headach; frequent attempts at retching, without actual vomiting; the bowels have not been opened for three days; tongue dry, and covered with a very white thick fur; urine very high-coloured; scalp hot; eyes slightly injected, and countenance suffused; abdomen full, and tolerant of pressure; no eruption on the surface of the body. There appears to be a slight difficulty in the enunciation, as if he were speaking thick; this is so slight, however, as not to have been previously observed by his comrades. Ordered to have the hair cut close, and an evaporating lotion applied constantly to the forehead; to have twenty grains of ipecacuanha powder immediately; after its operation, to take five grains of calomel; this to be followed by a senna draught after an interval of three hours.

Fourth day.- $\mathrm{He}$ vomited a large quantity of acid matter yesterday, and has not since been troubled with retching; the bowels, however, have not been opened yet. He passed a restless night, the difficulty of speaking gradually increasing; he appeared, however, quite sensible. Early this morning he had rather profuse hremorrhage from the nostrils, and since that ceased he has not spoken. He now lies with a dull, heavy expression of countenance, apparently unconscious of 